\title{
Microstructure and mechanical properties of autobody steel joined by friction stir spot welding
}

\author{
FARHOOD HEYDARI ${ }^{1}$, AHMAD ALI AMADEH ${ }^{2}$, OLATUNJI OLADIMEJI OJO ${ }^{3, * \mathbb{B}}$, \\ MOHAMMAD HOSSEIN HASANNIYA ${ }^{4}$ and MORTAZA TAMIZIFAR ${ }^{5}$ \\ ${ }^{1}$ Department of Materials Engineering, Science and Research Branch, Islamic Azad University, Tehran, Iran \\ ${ }^{2}$ School of Metallurgy and Materials Engineering, College of Engineering, University of Tehran, Tehran, Iran \\ ${ }^{3}$ Industrial and Production Engineering, Federal University of Technology Akure, Akure, Nigeria \\ ${ }^{4}$ Supplying Automotive Parts Co (SAPCO), Tehran, Iran \\ ${ }^{5}$ Materials and Metallurgical Engineering Department, Iran University of Science and Technology, Tehran, Iran \\ e-mail: ojooladimeji90@yahoo.com
}

MS received 27 September 2018; revised 8 December 2018; accepted 11 December 2018; published online 6 March 2019

\begin{abstract}
This work investigates the microstructural features and mechanical properties of joints of lowcarbon steel friction stir spot welded by changing tool rotational speed and dwell time. Microstructural evaluation, peeling, tension-shear and micro-hardness tests were employed to characterize the properties of the welded joints. The results show that an increase in the tool rotational speed promotes the formation of more weld flash, and it equally changes the flash morphology from ring flash to a combination of ring and serrated flashes. A fine immediate tool contact region is formed in the stir zone (SZ) and the width of the ITCR increases with the tool rotational speed and tensile-shear failure load. Besides the ITCR, the SZ uniquely consists of the shoulder undersurface region (SZ I) and vortex region (SZ II) with average grain sizes of about 10.9 and $16.66 \mu \mathrm{m}$, respectively. An increase in tool rotational speed improves the micro-hardness, and the average diameter of the weld nugget (from 4.5 to $5.5 \mathrm{~mm}$ ). Base metal-nugget interface failure $(650 \mathrm{rpm})$ and base metal neckinginduced failure $(1250 \mathrm{rpm})$ are the two forms of weld failure obtained in the welded samples.
\end{abstract}

Keywords. Friction stir spot welding (FSSW); low carbon steel; microstructural analysis; mechanical analysis.

\section{Introduction}

Friction stir welding (FSW) process was innovated at the Welding Institute (TWI) in 1991 [1, 2]. This invention makes the application and the feasibility of joining difficult-to-weld metals such as aluminium and magnesium alloys possible [3-6]. The development of high-wear-resistance tools makes the application of FSW process to be extended to materials with higher strength and melting point such as steel [7-10]. A few researchers have investigated the FSW of low-carbon, high-carbon, medium-carbon and duplex steels. FSW/friction stir spot welding (FSSW) of steels is a good prospect for modern manufacturing because porosity, hydrogen embrittlement, weld inclusions, solidification-induced residual stress and weak heat-affected zone (HAZ) are associated with fusion-based welding of steels. These defects can be inhibited via the joining of steels by FSW/FSSW process.

*For correspondence
According to Sun and Fujii [11], higher resistance to hydrogen embrittlement was observed in the stirred region of the SK 4 high-carbon steel. The FSW process caused no phase transformation in the weld of SK 4 high-carbon steel and the stirred region (of the weld) consisted of a homogeneously refined ferrite matrix with evenly dispersed cementite particles [11]. Fujii et al [12] revealed that the FSW process carried out on the ferriteaustenite two-phase region of carbon steels produced refined microstructure and the highest weld strength. Manvatkar et al [13] reported that the need for heat treatment of welded high-carbon steel can be potentially eliminated via the use of FSW process. Ductility degradation and harmful effect of martensite formation in fusion-welded carbon steel can be curtailed in FSW process. Emami et al [14] revealed that the constituent phases of ferrite and austenite in the stir zone (SZ) of SAF 2205 duplex stainless steel had some grain refinement and simple shear texture components. The austenitic phase of the steel had common recrystallization texture components of cube, Goss, S, P and Q. It was 
further affirmed that continuous dynamic recrystallization (CDRX) occurred in the aforementioned phases while static recrystallization (SRX) ensued in the austenite phase. Das et al [15] studied the FSSW of complex phase (CP) and ultrahigh-strength dual phase (DP) steels. It was reported that bainite and martensite were present in the SZ of the CP steel, while the SZ of the DP steel did not contain bainite. This disparity in the phase transformation was attributed to the effect of the alloying composition.

Some researchers investigated the thermal impact of the FSW process and cooling effect on the weld nugget of steel. Mironov et al [16] revealed that the thermal effect of the FSW process caused material softening in the HAZ and promoted martensite transformation in the SZ of the transformation-induced plasticity (TRIP) steel. The occurrence of these microstructural changes was adjudged to have caused rapid strain localization and premature failure under tensile loading condition. On the other hand, a combined effect of dissolution and spheroidization of the retained austenite, and recovery in bainitic ferrite, was affirmed to have caused the material softening in the HAZ of the steel. Imam et al [17] revealed that the distribution of peak temperature along the weld thickness of a mediumcarbon low-alloy S45C steel enforced microstructural variations at the top and bottom weld regions. Lath martensite and fine ferrite-pearlite structures were obtained at the former (top weld region) and the latter (bottom weld region), respectively. The amount of martensite is reported to decrease with an increase in the welding speed. Also, Imam et al [18] investigated FSW of medium-carbon steel under rapid cooling with liquid $\mathrm{CO}_{2}$ at a temperature below the A1 transformation temperature. The rapid cooling process improved the weld's mechanical properties, reduced the size of cementite particles and produced equiaxed ultrafine ferrite grains (less than $1 \mu \mathrm{m}$ ) due to the faster heat elimination process when compared with the welds subjected to natural cooling. Choi et al [19] examined the FSW of a high-carbon SK5 steel with and without a gas torch aimed at controlling cooling rate during the welding process. It was revealed that the use of a gas torch in welding the steel lowered the cooling rate and decreased the volume fraction of martensite structure and the weld hardness value.

Based on the existing literature [20-27], works on other steel joint features such as flash, bonded and nugget width and resistance of weld nugget to crack initiation and failure are major research windows that have not been exploited. This present study attempts to examine some of the aforementioned areas by conducting FSSW on a low-carbon steel sheet with a thickness of $1.2 \mathrm{~mm}$, which is the most current steel in Iran's auto industry for making car body. Microstructural analysis was conducted while peeling; tensile-shear and micro-hardness testings were performed on the welded samples for the mechanical properties.

\section{Experimental method}

Hot-rolled sheets of a low-carbon steel were used as the base metal (BM) for this research. The chemical composition of the steel sheet obtained by spectrometry is given in table 1 . The sheets were cut to the length of $105 \mathrm{~mm}$ and the width of $45 \mathrm{~mm}$ in order to obtain an overlapped area of $45 \mathrm{~mm}$ by $45 \mathrm{~mm}$ according to ANSI/AWS/SAE/D 8.9-97 standards as indicated in figure 1a. Tungsten carbide was employed as the tool material and a schematic of the welding tool is illustrated in figure $1 \mathrm{~b}$. Prior to the welding action, the surface of the cut sheets was cleaned by first applying a metallic brush and later acetone. The prepared samples were rigidly clamped to the backing plate in order to accommodate perpendicular travel of the tool into the sheet as shown in figure 2 .

The welding process was performed at tool rotational speeds of 1250 and $625 \mathrm{rpm}$, and dwell times of 1 and $4 \mathrm{~s}$. The tool plunge rate/speed was kept constant at $2.5 \mathrm{~mm} / \mathrm{s}$ while the applied force on the tool was made variable. Cross-sections of welds required for metallographic analyses were mounted in resin, ground, polished and etched in a Naytal solution (mixed with nitric acid and ethanol) for $5 \mathrm{~s}$. Microstructural analysis and imaging of weld samples were carried out using an optical microscope (Olympus BX60) equipped with Image Analyzer Aquino A14 software with a magnification of $100-2000 \times$. The ASTM grain size was determined at different weld zones via the use of the installed software on the microscope.

Peeling test was carried out on the fabricated welded joints as shown in figure 3a. The weld nuggets are generally asymmetrical in nature with slightly variable/nonconstant diameters due to the peeling effect (plasticization of the nugget area). Thus, the nugget diameters (weld buttons) of the joints were measured in distinct directions through the use of a caliper, and the average of the measured diameters was taken as the actual nugget diameter of the welded joint.

Vickers microhardness test was carried out under a load of $200 \mathrm{~g}$ and holding time of $15 \mathrm{~s}$ across the crosssection of the weldment. The tension-shear test was evaluated according to ANSI/AWS/SAE/D8.9-97 standards (use for evaluation of resistance-spot-welded joints) on an Instron 50982 tensile machine with a capacity of 10 tonnes and at a constant pulling speed of $2 \mathrm{~mm} / \mathrm{min}$. Each tensile test of a sample was repeated three times and the resultant average was employed as the actual

Table 1. Chemical composition of the low-carbon steel.

\begin{tabular}{lcccccc}
\hline Elements & $\mathrm{C}$ & $\mathrm{Al}$ & $\mathrm{Si}$ & $\mathrm{Mn}$ & $\mathrm{S}$ & $\mathrm{P}$ \\
\hline $\mathrm{wt} \%$ & 0.08 & 0.02 & 0.03 & 0.5 & 0.02 & 0.02 \\
\hline
\end{tabular}


(a)

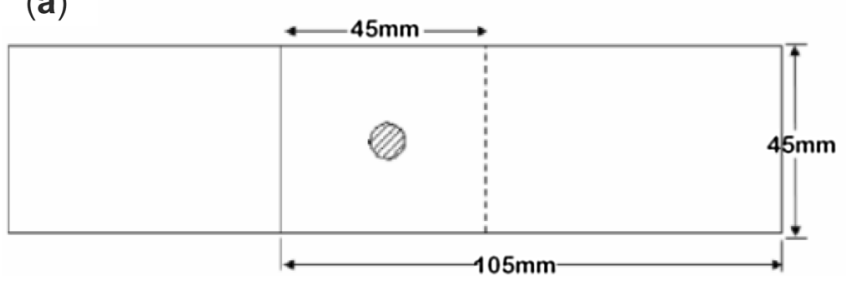

(b)

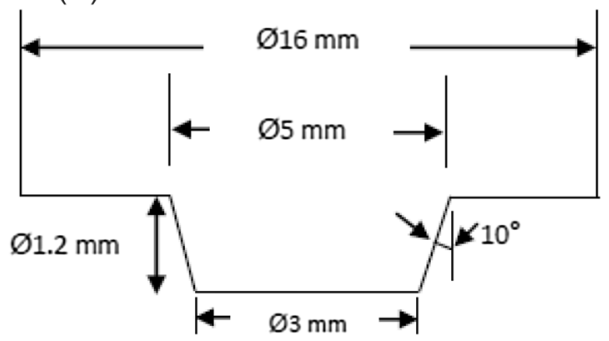

Figure 1. (a) Dimensions of tensile-shear test specimen. (b) Schematic tool.
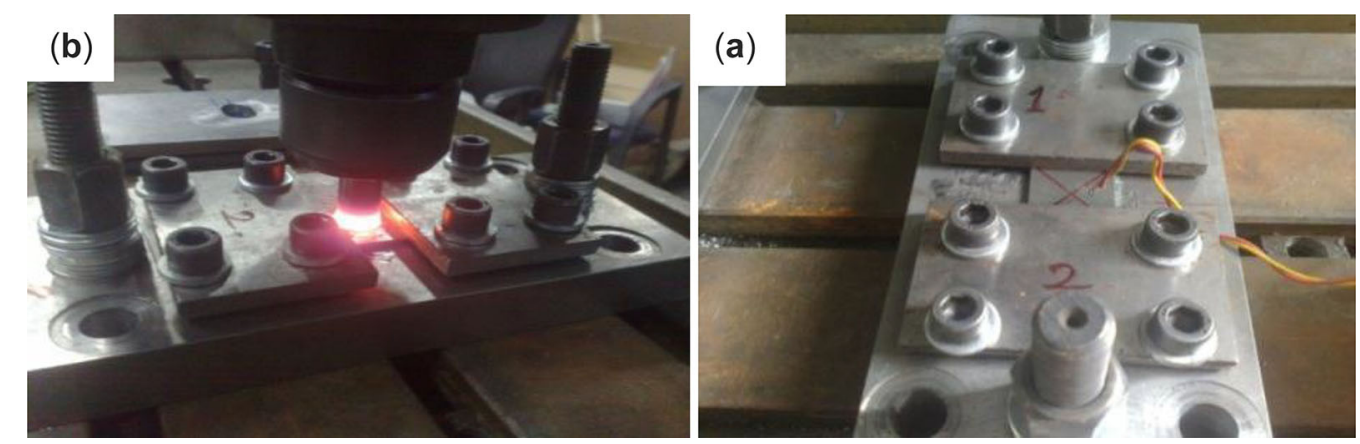

Figure 2. Welding set-up.
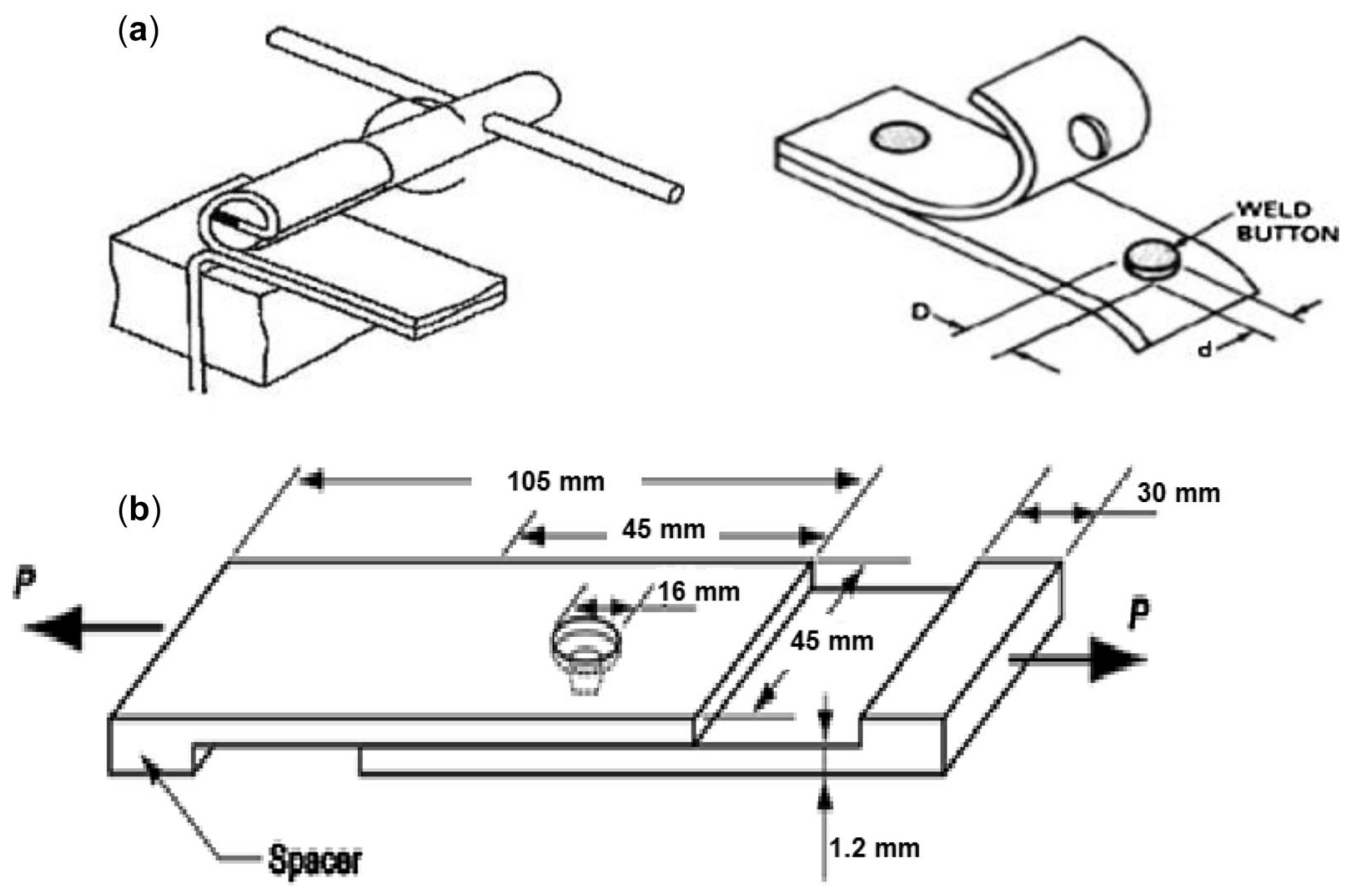

Figure 3. (a) Peeling test sample [28]. (b) Tensile-shear test sample.

tensile strength of the sample. The dimension and configuration of the tensile-shear test samples are shown in figure $3 b$. Two sheet spacers (having the same thickness as that of the BM) were held with the tensile specimen to prevent the rotation of joint position under axial loading of the welded joint. 


\section{Results and discussion}

\subsection{Macrostructure}

The formed flash around the weld nuggets is displayed in figure 4. Increasing the tool rotational speed from 625 to $1250 \mathrm{rpm}$ produced more weld flash around the circumference of the impinged tool area. Even flash ring and serrated flash are formed in the welds produced at $1250 \mathrm{rpm}$, whereas ring flash is formed at $625 \mathrm{rpm}$ (see figure 4). This implies that more heat input is introduced into the weld nugget at elevated temperature or at a high tool rotational speed, and this will consequently reduce the viscosity, and increase bulk material flow (plasticized material) and expulsion of more plasticized material out of the stirred zone (owing to the volume/amount of the induced plasticized material). This is in close agreement with the works of Oladimeji et al [29], and Ojo and Taban [30] as the tool rotational speed is affirmed to significantly control the expelled flash volume of friction stir spot welds. An increase in tool rotational speed is synonymous to an increase in the generated frictional heat input during the FSSW process [31, 32]. The frictionally heated up material (at higher tool rotational speed) has been reported to facilitate better material flowability owing to the reduced viscosity of the plasticized BM [29]. The plasticized material at the SZ undergoes upward extrusion or squeezeout (around the rotating tool) at high tool rotational speed or temperature. In addition, induced frictional and deformational heat input forms a dark thermal ring around the nugget spot area (see figure 4). The dark thermal ring is the peripheral region enveloping the weld nugget/SZ, and it has a unique colouration different from that of the BM as revealed in the surface appearance depicted in figure 4 . The region enclosed within the even flash ring is the SZ or weld nugget. The region between the even flash ring and the thermal ring can be adjudged as the thermally affected region within the weldment due to the different colouration between the region and that of the BM.

Figure 5 reveals a unique region (plasticized and refined region) in the stirred zone of the spot weld adjacent to the periphery of the retracted welding tool space. This region is referred to as the immediate tool contact region (ITCR) in this paper. The boundary of the fine ITCR to the other part of the stirred region (of the joint) is annotated with dotted black lines. The volume/size or width of the ITCR directly increases with the level of tool rotational speed. This occurrence may be due to the dominant frictionally (contact) induced thermal effect and deformational effect of the welding tool on the BM as compared with the other part of the SZ with possible dominant deformational flow effect. The asymmetric complex flow of the plasticized material around the hard tool surface (shoulder and pin surfaces) may forcefully constrain the material flow space and enforce further several material deformations and recrystallization of the plasticized BM around the tool surface
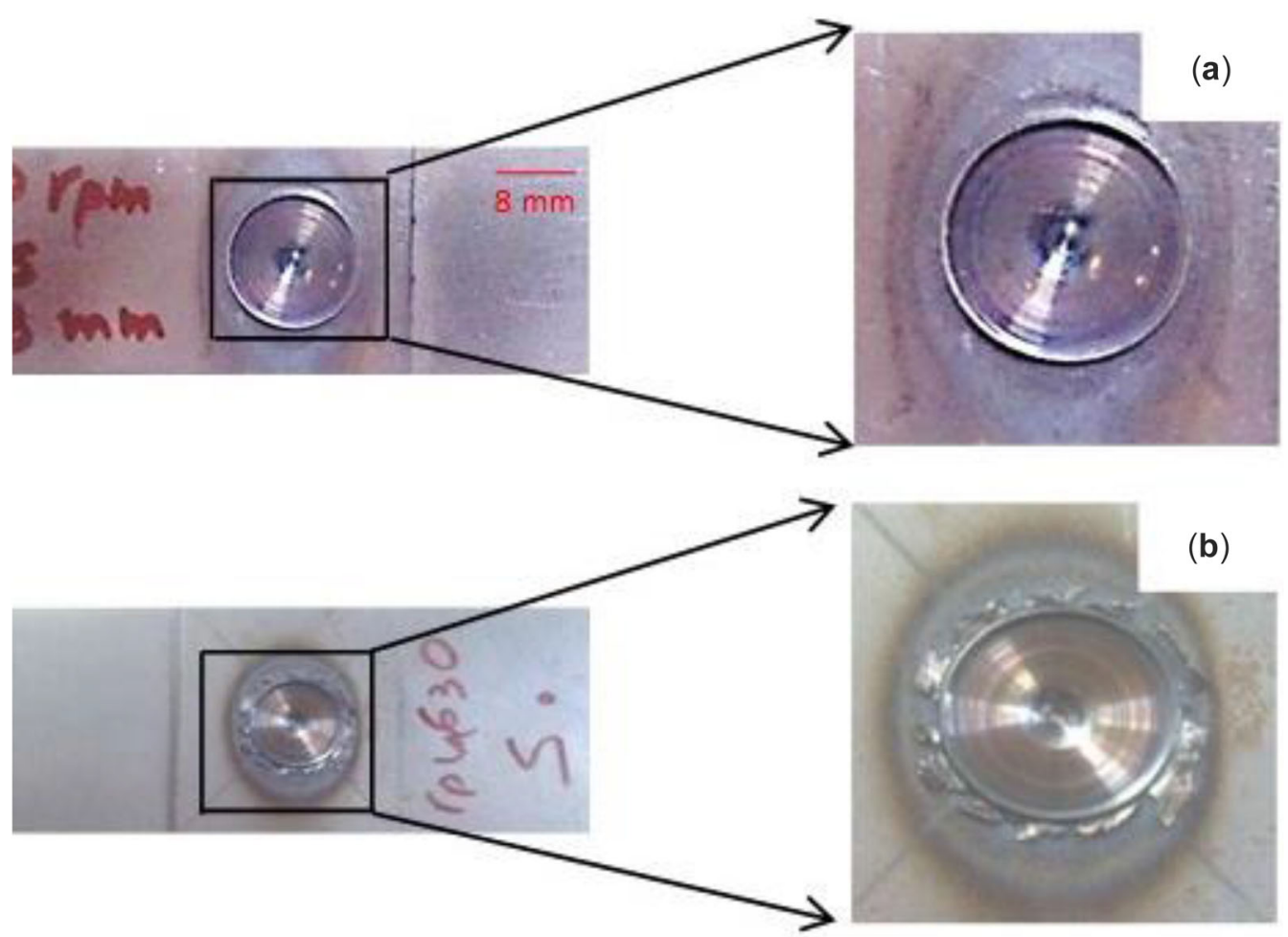

Figure 4. Macrostructure of the weld surface at a dwell time of $1 \mathrm{~s}$ and at tool rotational speed of (a) $625 \mathrm{rpm}$ and (b) $1250 \mathrm{rpm}$. 

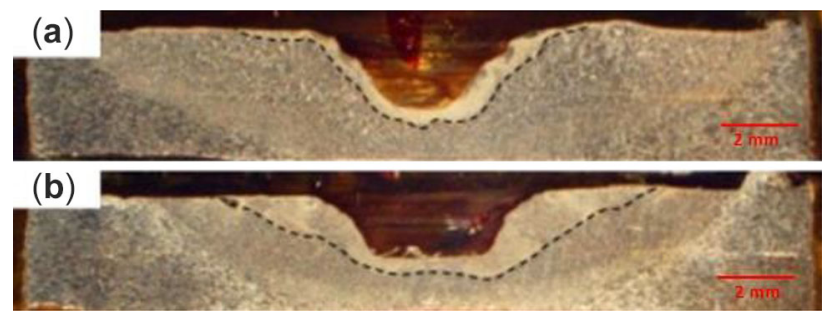

Figure 5. Changes in the stir zone volume with tool rotation speed at a constant dwell time of $1 \mathrm{~s}$ : (a) $625 \mathrm{rpm}$ and (b) $1250 \mathrm{rpm}$.

region to form fine ITCR. The introduction of more heat input (temperature rise) at a high rotational speed $(1250 \mathrm{rpm})$ occurs at the shoulder undersurface and this may be likely responsible for the larger ITCR width (in the tool shoulder region) in figure $5 \mathrm{~b}$. Also, the tool shoulder has been identified to perform shearing and compressive effects on the BM while the pin performs only shearing effect on the BM [29]. The outward/upward spinning material motion at the pin periphery is compressed by the tool shoulder, and the centrifugal effect [29] or radial stretching of the material [33] (at the tool shoulder) facilitates the material flow to the shoulder edge. Thus, interzone material transport is inevitable in the ITCR or the tool-material contact region [29] and the influence of high tool rotational speed on ITCR could be responsible for the larger ITCR in figure 5b as compared with figure 5a.

\subsection{Microstructure}

Figure 6 shows the cross-sections of the different metallurgical zones of the welded joint produced at $1250 \mathrm{rpm}$ and dwell time of $1 \mathrm{~s}$. The BM shows elongated coaxial grains with an average diameter of about $45.65 \mu \mathrm{m}$ (see figure $6 a$ ). The elongation of the grains is along the rolling direction of the steel sheet.

The HAZ is located between the thermo-mechanically affected zone (TMAZ) and the BM. This is the region between the dark thermal ring and the tool-impinged zone illustrated in figure 4. The HAZ consists of relatively fine and coaxial grains with an average size of about $11.2 \mu \mathrm{m}$ (in the adjacent region closer to the TMAZ). These grains are coarser when compared with the grains of the SZ's upper zone (the area closer to pin) and finer than that of the TMAZ. The HAZ receives lower heat input by conduction heat transfer due to its larger distance from the shoulder face and the rotating pin, and SRX is noted to have occurred in this zone.

The TMAZ is shown in figure $6 \mathrm{~d}$ is located between the SZ and the HAZ. The TMAZ consists of equiaxed grains with an average size of about $13.54 \mu \mathrm{m}$. Hybrid recrystallization can be said to have occurred in this region due to the simultaneous influences of the thermal and mechanical effects.
Two distinct SZs are observed in the weld cross-section as indicated in figure $6 \mathrm{e}$ and $\mathrm{f}$. They are the regions beneath the shoulder surface and adjacent to the pin periphery (SZ I), and the vortex region of the tool pin (SZ II). The finest equiaxed and recrystallized grains with an average size of $10.9 \mu \mathrm{m}$ were observed in the region closer to the shoulder face and the periphery of the pin length (SZ I). An average grain size of about $16.66 \mu \mathrm{m}$ is attained in the region around the pin vortex or the part beneath the pin head (SZ II). The grain refinement in these two distinct regions is attributed to hybrid recrystallization (plastic deformation and frictional effect).

The upper surface of the SZ had the highest temperature during the FSSW process due to the intense frictional energy between the interfacial surface of the BM and the tool shoulder [29, 34, 35]. The exposed face of the alloy to the shoulder surface is adjudged to experience rapid cooling as the tool is retracted from the welded spot due to convection and conduction heat transfer mode. This consequently ensures that there is not enough time for the recrystallized grains to coarsen/grow at the SZ I and consequently, fine equiaxed microstructures are attained (at the SZ I). More grain boundaries are thus associated with the SZ I of the weld and this could lower the corrosion resistance of the welded joint. On the other hand, steel has a lower thermal conduction coefficient $(55 \mathrm{w} / \mathrm{mK})$ when compared with aluminium $(255 \mathrm{w} / \mathrm{mK})$. This implies that the cooling rate in steel cannot be as large as that of $\mathrm{Al}$ alloy. The recrystallized grains of the SZ II (area underneath the pinhead/vortex flow) is adjudged to have more time to grow due to low cooling rate after the pin retraction from the sheets and a thermal gradient would ensue at the stirred zone (SZ II). Owing to this occurrence, a slight grain growth is attained at the SZ II as compared with that of SZ I. A coarse microstructure may decrease the mechanical properties (fatigue) of weldments [36].

\section{2a Grain size comparison of different samples at distinct} weld zones: Figure 7 shows the relative appraisal of the average grain sizes of the different weld regions at different tool rotational speeds. The compressive and rotational effect of the tool enforces grain recrystallization or refinement in the steel BM when compared with that of unstirred BM (see figure 7). Increase in tool rotational speed from 625 to $1250 \mathrm{rpm}$ directly increases the average grain sizes of the weld zones. This occurrence is due to the impact of heat input/tool rotational speed on the grain size. More thermal or heat input is adjudged to be induced in the weld samples at $1250 \mathrm{rpm}$. This will consequently cause grain coarsening and reduced dislocation density in the weld zones. The TMAZ is the region with the highest/maximum grain size in the weld nugget of the BM. This may be due to the impact of mechanical/deformational effect on the weld's microstructure. Figure 7 reveals that the ITCR is the region with the least grain size and away from this part of the SZ, grains grow gradually into the SZ and the TMAZ. 

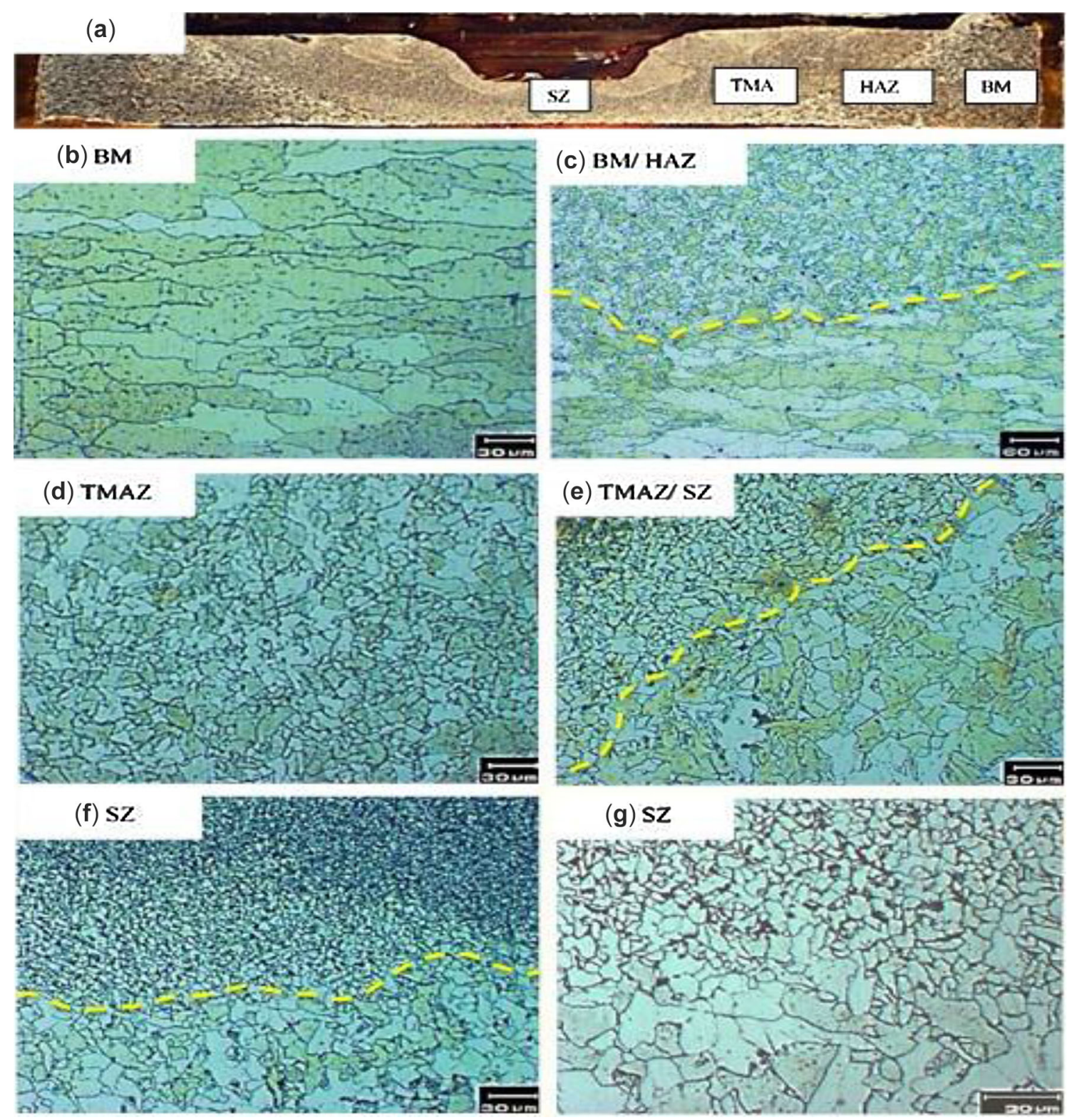

Figure 6. Different weld zones across the weld nugget.

This confirms that the ITCR region directly exposed to tool surface experiences further grain refinement and higher dislocation density.

\subsection{Microhardness test}

Figure 8 reveals the micro-hardness distribution values across the weld zones. The BM has the least hardness value of about $126 \mathrm{HV}$, essentially due to its large elongated grain sizes. Thermal or frictional effect on the steel progressively increases the hardness values from the BM $(126 \mathrm{HV})$ to the ITCR/SZ. The region directly close to the weld keyhole is the ITCR region and this reveals the maximum hardness value. Alternatively, a gradual decline in hardness values occurs from the ITCR/SZ region down to the $\mathrm{BM}$ in the weld sample obtained at $1250 \mathrm{rpm}$ whereas that of $650 \mathrm{rpm}$ shows relatively close values between the TMAZ and the HAZ.

Increase in tool rotational speed from 625 to $1250 \mathrm{rpm}$ caused a grain growth as revealed in figure 7 , and this is expected to have a declining effect on the hardness values (obey Hall-Petch relationship). However, hardness improvement is attained with an increase in tool rotational speed (see figure 8). Table 2 compares the hardness values in different weld zones and it shows that 244.107 and 175.39 $\mathrm{HV}$ are obtained in the SZs at 1250 and $650 \mathrm{rpm}$, respectively. This occurrence is likely due to the formation 


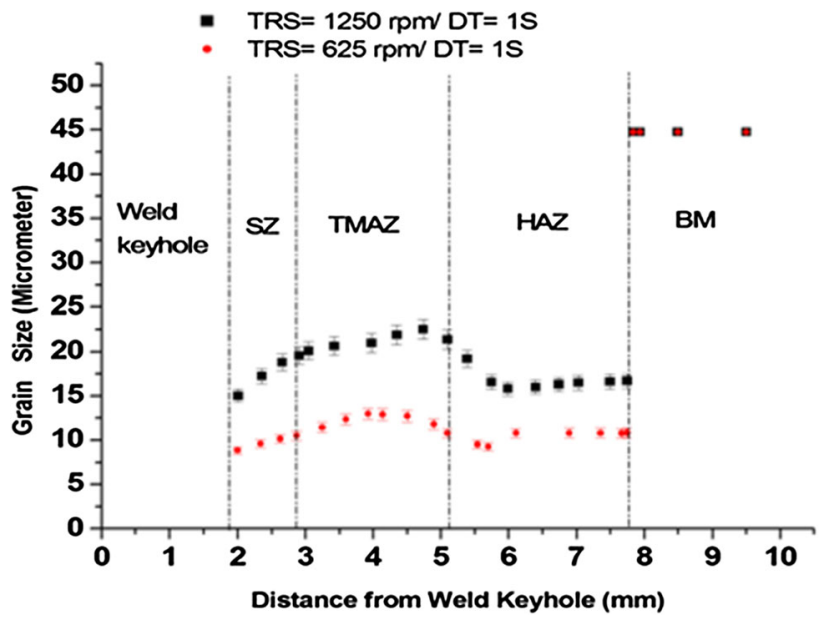

Figure 7. Changes in grain size from the centre of the weld.

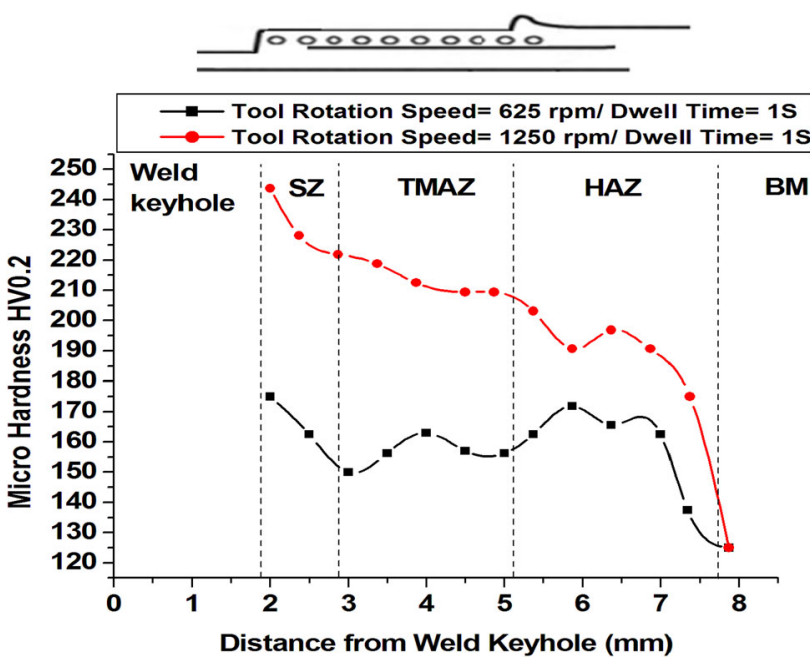

Figure 8. Micro-hardness values across weld cross-sections.

of martensitic structure in the stirred region of the weld at high tool rotational speed $(1250 \mathrm{rpm})$. This brittle structure has high resistance against indentation and this homogeneous dispersion of this hard phase within the structure of the BM could have resulted in the higher hardness values in the weld samples at $1250 \mathrm{rpm}$.

\subsection{Peeling and tensile-shear tests}

Figure 9 shows the fracture and weld button of a weld nugget after its subjection to peeling test. The assessment of the weld buttons reveals that an increase in the tool rotation speed from 625 to $1250 \mathrm{rpm}$ directly improves the average diameter of the weld nugget (weld button) from 4.5 to $5.5 \mathrm{~mm}$. This occurrence may be attributed to the larger SZ or ITCR at a high tool rotational speed. The induced heat input and stirring effect of the tool at higher tool rotational
Table 2. Maximum hardness values in different weld zones.

\begin{tabular}{lcc}
\hline $\begin{array}{l}\text { Weld } \\
\text { zones }\end{array}$ & $\begin{array}{c}\text { The greatest amount of } \\
\text { hardness in sample A } \\
(650 \mathrm{rpm})\end{array}$ & $\begin{array}{c}\text { The greatest amount of } \\
\text { hardness in sample B } \\
(1250 \mathrm{rpm})\end{array}$ \\
\hline SZ & 175.39 & 244.107 \\
TMAZ & 163.27 & 221.91 \\
HAZ & 172.32 & 206.8 \\
Base & 125.72 & 125.72 \\
metal & & \\
\hline
\end{tabular}

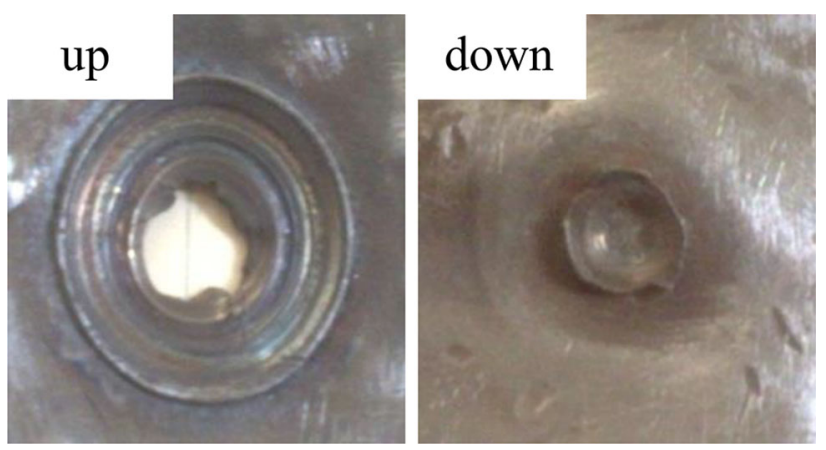

Figure 9. Peeling tested sample.

speed could enforce larger material plasticization and subsequently SZ enlargement would ensue. Besides, the minimum admissible diameter of a weld nugget should be equal to $4 \sqrt{ } t$, where $t$ is the thickness of the sheet to be joined. The customary thickness of the used sheet in Iran auto industry that was utilized in this study is $1.2 \mathrm{~mm}$. Therefore, the minimum average of weld nugget diameter should be $4.38 \mathrm{~mm}$. The weld nugget sizes produced are larger than $4.38 \mathrm{~mm}$, and the obtained welded joints are reckoned to be acceptable.

Figure 10 shows the force-displacement curves and the fracture modes of the steel weld samples. Tensile shear loads of about 8874 and $8372 \mathrm{~N}$ were obtained in the weld samples produced at tool rotational speeds of 1250 and $650 \mathrm{rpm}$, respectively. The presence of larger ITCR/SZ in the weld obtained at $1250 \mathrm{rpm}$ when compared with that of $650 \mathrm{rpm}$ could be responsible for the observed higher tensile shear load. This occurrence enhances larger bonded width and an enlarged average diameter of the weld nugget (weld button) as observed from the peeling test. Besides, the increase in heat input (tool rotational speed) could have ensured sufficient plasticization, inter-material flow/diffusion and stronger bonding in the weld sample $(1250 \mathrm{rpm})$.

Two different forms of ductile fracture or failure occur in the respective welds (see figure 10). They are BM-nugget interface failure $(650 \mathrm{rpm})$ and BM-necking-induced failure (1250 rpm). Displacement at the onset of failure is about 15.50 and $12.23 \mathrm{~mm}$ in the weld samples produced at 1250 and $650 \mathrm{rpm}$, respectively. This confirms that the bonded 


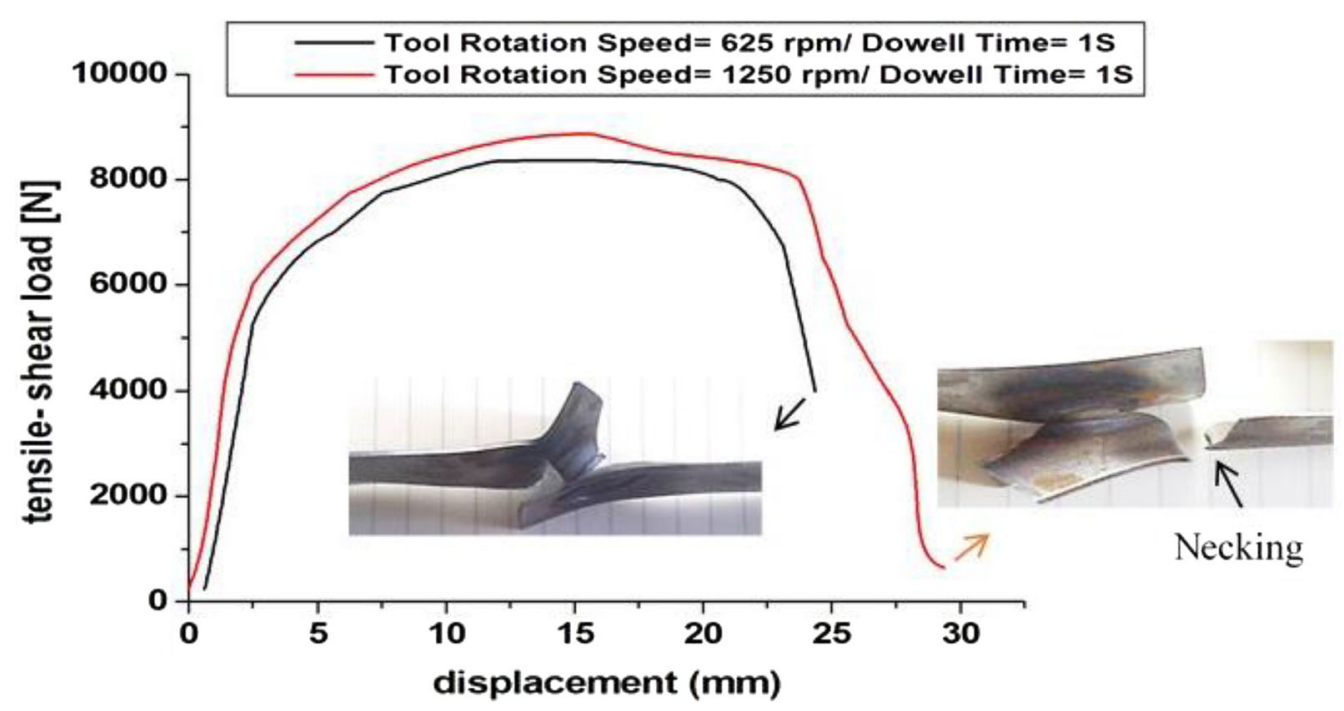

Figure 10. Force-displacement curve of the weld samples.

joint/weld width (1250 rpm) undergoes plasticization but without crack initiation, while that of the other weld (650 rpm) plasticizes, initiates a crack and fails along the interfacial bonded line. The occurrence of BM-necking-induced failure implies that the weld nugget or bonded joint area resists failure under axial loading condition. Necking of the BM emerges and this acts as the crack nucleation zone in the weldment. The progressive loading condition causes crack growth along the plasticized BM (necked region) and results in the final weld failure in the weld sample produced at $1250 \mathrm{rpm}$. On the other hand, BM-nugget interface failure is adjudged to have occurred in the weld (650 rpm) due to the inability of the bonded zone to resist axial loading. The crack could have been initiated along the interfacial line and grown around the circumferential weld button and into the BM for the final weld failure.

\section{Conclusion}

The joining of the low-carbon steel was successfully achieved via the use of the friction stir spot welding process. The findings from this research are summarized as follows:

1. Increase in tool rotational speed enforces the formation of more weld flash around the tool-impinged zone. This is attributed to the increased heat input and plasticization of the base metal (BM).

2. A combination of ring and serrated flashes is formed at a high tool rotational speed while even ring flash is produced at reduced tool rotational speed.

3. A unique and fine immediate tool contact region (ITCR) is created in the stir zone (SZ) of the low-carbon steel. The volume or width of the ITCR directly increases with the level of tool rotational speed.
4. Grain sizes of the SZ vary between the shoulder undersurface region (SZ I) and the vortex region of the tool pin (SZ II). SZ I and SZ II have average grain sizes of about 10.9 and $16.66 \mu \mathrm{m}$, respectively. This occurrence is attributed to the principal heat input and recrystallization in the shoulder undersurface region.

5. Increase in tool rotational speed improves the microhardness values of the low-carbon steel.

6. Increase in the tool rotation speed from 625 to $1250 \mathrm{rpm}$ directly improves the average diameter of the weld nugget from 4.5 to $5.5 \mathrm{~mm}$.

7. Tensile shear load increases from 8372 to $8874 \mathrm{~N}$ as the tool rotational speed is increased from 650 to $1250 \mathrm{rpm}$.

8. BM-nugget interface failure and BM-necking-induced failure are the two forms of weld failure obtained in the welded samples. BM-necking-induced failure produces better tensile shear failure load.

\section{Acknowledgements}

The authors would like to thank SAPCO Corporation for the financial support received for this research. The authors also thank Mr F Kargar and Mr Paranj for their assistance in the experiments.
Nomenclature
BM base metal
CDRX continuous dynamic recrystallization
$\mathrm{CP} \quad$ complex phase
DP dual phase
FSSW friction stir spot welding
FSW friction stir welding
HAZ heat-affected zone 
ITCR immediate tool contact region of the stir zone

SRX static recrystallization

SZ stir zone

SZ I shoulder undersurface region of the stir zone

SZ II vortex region of the stir zone

TMAZ thermo-mechanically affected zone

TRIP transformation-induced plasticity

\section{References}

[1] Thomas W M 1991 Friction stir butt welding. Inter. Pat. App. No. PCT/GB92/022-0

[2] Kano Y, Inuzuka M, Yamashita S, Nakashima Y, Nagao Y and Iwashita T 2004 Spot joining method and spot joining device. U.S. Pat. No. 6,832,713. 21

[3] Gerlich A, Avramovic-Cingara G and North T H 2006 Stir zone microstructure and strain rate during Al 7075-T6 friction stir spot welding. Metall. Mater. Trans. A 37: 2773-2786

[4] Zhang Z, Yang X, Zhang J, Zhou G, Xu X and Zou B 2011 Effect of welding parameters on microstructure and mechanical properties of friction stir spot welded 5052 aluminum alloy. Mater. Des. 32: 4461-4470

[5] Shen J, Min D and Wang D 2011 Effects of heating process on the microstructures and tensile properties of friction stir spot welded AZ31 magnesium alloy plates. Mater. Des. 32: 5033-5037

[6] Yuan W, Mishra R S, Webb S, Chen Y L, Carlson B, Herling D R and Grant G J 2011 Effect of tool design and process parameters on properties of $\mathrm{Al}$ alloy 6016 friction stir spot welds. J. Mater. Sci. Technol. 211: 972-977

[7] Feng Z, Santella M L, David S A, Steel R J, Packer S M, Pan T, Kuo M and Bhatnagar R S 2005 Friction stir spot welding of advanced high-strength steels-a feasibility study. SAETech. Paper No. 2005-01-1248

[8] Khan M I, Kuntz M L, Su P, Gerlich A, North T and Zhou Y 2007 Resistance and friction stir spot welding of DP600: a comparative study. Sci. Technol. Weld. Join. 12: 175-182

[9] Hovanski Y, Santella M L and Grant G J 2007 Friction stir spot welding of hot-stamped boron steel. Scr. Mater. 57: 873-876

[10] Baek S, Choi D, Lee C, Ahn B, Yeon Y, Song K and Jung S 2010 Structure-properties relations in friction stir spot welded low carbon steel sheets for lightweight automobile body. Mater. Trans. 51: 399-403

[11] Sun Y and Fujii H 2015 Improved resistance to hydrogen embrittlement of friction stir welded high carbon steel plates. Int. J. Hydrogen Energy 40: 8219-8229

[12] Fujii H, Cui L, Tsuji N, Maeda M, Nakata K and Nogi K 2006 Friction stir welding of carbon steels. Mater. Sci. Eng. A 429: 50-57

[13] Manvatkar V, De A, Svensson L E and DebRoy T 2015 Cooling rates and peak temperatures during friction stir welding of a high-carbon steel. Scr. Mater. 94: 36-39

[14] Emami S, Saeid T and Khosroshahi R A 2018 Microstructural evolution of friction stir welded SAF 2205 duplex stainless steel. J. Alloys Compd. 739: 678-689
[15] Das H, Mondal M, Hong S, Lim Y and Lee K 2018 Comparison of microstructural and mechanical properties of friction stir spot welded ultra-high strength dual phase and complex phase steels. Mater. Charact. 139: 428-436

[16] Mironov S, Sato Y S, Yoneyama S, Kokawa H, Fujii H T and Hirano S 2018 Microstructure and tensile behaviour of friction-stir welded TRIP steel. Mater. Sci. Eng. A 717: 26-33

[17] Imam M, Ueji R and Fujii H 2015 Microstructural control and mechanical properties in friction stir welding of medium carbon low alloy S45C steel. Mater. Sci. Eng. A 636: 24-34

[18] Imam M, Ueji R and Fujii H 2016 Effect of online rapid cooling on microstructure and mechanical properties of friction stir welded medium carbon steel. J. Mater. Sci. Technol. 230: 62-71

[19] Choi D, Lee C, Ahn B, Choi J, Yeon Y, Song K, Hong S, Lee W, Kang K and Jung S 2011 Hybrid friction stir welding of high-carbon steel. J. Mater. Sci. Technol. 27: 127-130

[20] Venkatesh K M, Arivarsu M, Manikandan M and Arivazhagan N 2018 Review on friction stir welding of steels. Mater. Today Proc. 5: 13227-13235

[21] Fei X and Wu Z 2018 Research of temperature and microstructure in friction stir welding of Q235 steel with laser-assisted heating. Results Phys. 11: 1048-1051

[22] Mahmoudiniya M, Kokabi A H, Kheirandish S and Kestens L A I 2018 Microstructure and mechanical properties of friction stir welded ferrite-martensite DP700 steel. Mater. Sci. Eng. A 737: 213-222

[23] Pereira daCunha P H C, Lemos G V B, Bergmann L, Reguly A, dosSantos J F, Marinho R R and PizaPaes M T 2018 Effect of welding speed on friction stir welds of GL E36 shipbuilding steel. J. Mater. Res. Technol. https://doi.org/10. 1016/j.jmrt.2018.07.014

[24] Ahmad B, Galloway A and Toumpis A 2018 Advanced numerical modelling of friction stir welded low alloy steel. $J$. Manuf. Process. 34: 625-636

[25] Argade G R, Shukla S, Liu K and Mishra R S 2018 Friction stir lap welding of stainless steel and plain carbon steel to enhance corrosion properties. J. Mater. Process. Technol. 259: 259-269

[26] Sun Y F, Fujii H, Sato Y and Morisada Y 2018 Friction stir spot welding of SPCC low carbon steel plates at extremely low welding temperature. J. Mater. Sci. Technol. https://doi. org/10.1016/j.jmst.2018.11.011

[27] Dawson H, Serrano M, Cater S and Jimenez-Melero E 2018 Characterization of ODS steel friction stir welds and their abnormal grain growth behavior. Fusion Eng. Des. 135: 174-182

[28] ANSI/AWS/SAE 1997 Recommended practices for evaluating the resistance spot welding behavior of automotive sheet steel materials.

[29] Oladimeji O O, Taban E and Kaluc E 2016 Understanding the role of welding parameters and tool profile on the morphology and properties of expelled flash of spot welds. Mater. Des. 108: 518-528

[30] Ojo O O and Taban E 2018 Hybrid multi-response optimization of friction stir spot welds: failure load, effective bonded size and flash volume as responses. Sådhanå 43: 98

[31] Ojo O O 2018 Explicit dynamic simulation of FSSW of AA6061 aluminium alloy: effect of friction coefficients. In: 
Proceedings of the 2018 SEET Annual Conference, pp. 524-534

[32] De Leon M and Shin H S 2016 Material flow behaviours during friction stir spot welding of lightweight alloys using pin and pinless tools. Sci. Technol. Weld. Join. 21: $140-146$

[33] Reilly A, Shercliff H, Chen Y and Prangnell P 2015 Modelling and visualization of material flow in friction stir spot welding. J. Mater. Process. Technol. 225: 473-484
[34] Ojo O O, Taban E and Kaluc E 2015 Friction stir spot welding of aluminium alloys: a recent review. Mater. Test. 57: 609-627

[35] Nandan R, DebRoy T and Bhadeshia H K D H 2008 Recent advances in friction-stir welding process, weldment structure and properties. Prog. Mater. Sci. 53: 980-1023

[36] Cui G R, Ma Z Y and Li S X 2008 Periodical plastic flow pattern in friction stir processed Al-Mg alloy. Scr. Mater. 58: 1082-1085 